УДК 621:662.6

\title{
ТЕПЛОВАЯ ИНТЕГРАЦИЯ АММИАЧНОГО ХОЛОДИЛЬНОГО АГРЕГАТА В КОММУНАЛЬНУЮ СИСТЕМУ ЗДАНИЙ
}

\author{
(C) 2013 г. С. А. Болдырев, А. О. Гарев*, Й. Й. Клемеш**, Л. Л. Товажнянский, \\ П. А. Капустенко, А. Ю. Перевертайленко*, О. П. Арсеньева* \\ Национальный технический университет "Харьковский политехнический институт” \\ * АO “Содружсество-T”, г. Харьков, Украина \\ ** Центр интеграции и интенсификации процессов - СРI ${ }^{2}$ \\ Научно-исследовательский институт химической технологии - МÜККІ, Университет Паннония, Веспрем, Венгрия \\ stas.boldyryev@gmail.com \\ Поступила в редакцию 24.09.2012 г.
}

\begin{abstract}
Показана возможность использования низкопотенциального тепла аммиачного холодильного цикла. Предложен проект энергоэффективной системы теплообменных аппаратов для подогрева воды и воздуха в муниципальных зданиях. Рассмотрена возможность увеличения давления аммиака для увеличения рекуперации тепла в системе и снижения нагрузки систем подогрева и охлаждения. Приведен выбор минимальной разности температур в системе теплообменных аппаратов. Рассчитана экономическая эффективность реализации проекта реконструкции.
\end{abstract}

DOI: $10.7868 / \mathrm{S} 0040357113010028$

\section{ВВЕДЕНИЕ}

Значительное увеличение стоимости энергоресурсов и повышение уровня выбросов двуокиси углерода в окружающую среду обусловило необходимость в разработке решений для увеличения энергоэффективности существующих производств [1]. Снижение потребления энергоресурсов и уменьшение вредных выбросов в атмосферу напрямую связано с работоспособностью и устойчивостью промышленных предприятий [2]. Эта проблема наиболее остро ощущается в производственных и перерабатывающих отраслях народного хозяйства. Для этих отраслей разработка таких методов уже давно является приоритетом развития [3]. Такие методы и их промышленное применение представлены в [4, 5]. Первые [4] связаны с построением сложных математических моделей химико-технологических систем и использованием большого количества переменных. Другие [5] используют системный подход для повышения энергоэффективности промышленных предприятий. Для жилищно-коммунального сектора эта проблема не является исключением, особенно когда речь идет об источниках теплоты низкого потенциала. В работе [6] показана оценка эффективности применения технологий для утилизации сбросного тепла. Такие источники могут быть использованы для удовлетворения потребностей нагрева в системах зданий. Одним из наиболее эффективных методов для утилизации низкопотенциального тепла является применение тепловых насосов [7]. Более детально приме- нение тепловых насосов и оценка их эффективности даны в работах $[8,9]$. В [8] дан обзор применения тепловых насосов и их эффективности. В работе [9] представлены результаты применения тепловых насосов в США.

Холодильные системы супермаркетов используют аммиачные холодильные машины для системы заморозки, охлаждения и хранения продуктов. Супермаркеты обычно располагаются вблизи густозаселенных жилых микрорайонов. Во время работы подобных аммиачных агрегатов большое количество низкопотенциального тепла не используется и сбрасывается в атмосферу через систему охлаждения. С другой стороны, в системах обогрева, кондиционирования и водоснабжения зданий существует потребность в подводе тепла. Однако температурные режимы потребителей теплоты зачастую такие, что использование сбросного тепла аммиачного цикла не всегда целесообразно. Технология утилизации низкопотенциального тепла для других производственных нужд была описана в работе [10]. Но оптимальное решение сложно найти без детального анализа системы производственных потоков, теплообмена на различных температурных уровнях и системы рекуперации тепла. Одним из наиболее эффективных методов для достижения оптимальной энергоэффективности является пинч-анализ [11-13]. Он основан на термодинамическом анализе системы технологических потоков и создании схем предприятий с учетом стоимости энергоносителей и оборудования. Эта ме- 
Таблица 1. Параметры технологических потоков для исходного процесса

\begin{tabular}{|c|c|c|c|c|c|c|c|c|c|}
\hline № & Название потока & Тип & $t_{S},{ }^{\circ} \mathrm{C}$ & $t_{T},{ }^{\circ} \mathrm{C}$ & $G, \mathrm{~T} / \mathrm{ч}$ & $\begin{array}{c}C_{p}, \\
\text { КДж/(кГ К) }\end{array}$ & $\begin{array}{c}r, \\
\text { кДж/кГ }\end{array}$ & $C P, \mathrm{\kappa B} / \mathrm{K}$ & $\Delta H, \mathrm{\kappa} \mathrm{B}_{\mathrm{T}}$ \\
\hline \multirow[t]{3}{*}{1} & Охлаждение аммиака & & 155 & 30 & 3.194 & 3.250 & 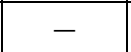 & 2.883 & 360.43 \\
\hline & Конденсация аммиака & Горячий & 30 & 30 & 3.194 & - & 1146 & - & 1016.76 \\
\hline & Охлаждение жидкого аммиака & Горячий & 30 & 20 & 3.194 & 4.750 & - & 4.214 & 42.14 \\
\hline 2 & Подогрев воды & Холодный & 15 & 60 & 15.000 & 4.190 & - & 17.458 & 785.63 \\
\hline 3 & Подогрев воздуха & Холодный & 10 & 30 & 50.000 & 1.005 & - & 13.958 & 279.17 \\
\hline 4 & Воздух для тепловых завес & Холодный & 10 & 55 & 25.000 & 1.005 & - & 6.979 & 314.06 \\
\hline
\end{tabular}

тодология имеет весьма широкое применение при производстве и хранении продуктов питания, как было продемонстрировано в публикациях различных исследователей [1]. Одни рассматривают интеграцию тепловых машин как многоуровневую задачу [14]. Другие показывают эффективность размещения тепловых машин совместно с интеграцией систем разделения и систем когенерации [15].

Ранее в работе [16] была показана возможность интеграции аммиачного холодильного цикла в тепловую схему сыро-молочного производства, что дало сокращение затрат на энергоносители на $65 \%$ за счет улучшения тепловой интеграции. В данной работе изучается возможность использования теплоты конденсации аммиачной холодильной машины супермаркета для существующих потребителей тепла. Рассмотрена возможность использования теплоты перегрева аммиака и теплоты конденсации. Далее изучается возможность дополнительного сжатия аммиака для наиболее полного использования теплоты конденсации аммиака. Для анализа использована методология интеграции процессов, которая позволяет снизить энергопотребление и построить теплообменную сеть с учетом минимальной общей приведенной стоимости.

\section{МОДЕЛИРОВАНИЕ ПРОЦЕССА}

Холодильный агрегат супермаркета представляет собой традиционную аммиачную холодильную машину [17]. Полученные производственные данные позволили построить компьютерную модель исследуемого холодильного агрегата с помощью программы UniSim Design [18]. Это дало возможность уточнить температуры, давления и расходы хладагента и получить недостающие теплофизические свойства. Давления аммиака на входе и выходе компрессора соответственно равны 196 и 1200 кПа, холодопроизводительность агрегата составляет 3956 кДж/ч. Технологические потоки исследуемого процесса и их теплофизические свойства приведены в табл. 1.
Модель аммиачного холодильного цикла показана на рис. 1. На данный момент тепло перегрева и конденсации аммиака отводится охлаждающей водой и сбрасывается в окружающую среду. Это хорошо видно на составных кривых существующего процесса (рис. 2). Для подогрева всех холодных потоков необходимо 1379 кВт, а для охлаждения горячих потоков, представленных горячей составной кривой, - 1419 кВт, область рекуперации тепловой энергии полностью отсутствует.

\section{ТЕПЛОВАЯ ИНТЕГРАЦИЯ}

Интеграция холодильного цикла. Сдвижка составных кривых до допустимого значения минимальной температурной разницы $\left(\Delta t_{\min }\right)$ между технологическими потоками дает возможность получить максимальную рекуперацию тепловой энергии в системе.

Допустимая минимальная разница между теплоносителями для существующего теплообменного оборудования составляет $5^{\circ} \mathrm{C}$. Составные кривые процесса с минимальным температурным сближением, равным $5^{\circ} \mathrm{C}$, представлены на рис. 3 .

Составные кривые показывают, что рекуперация тепловой энергии для существующей системы технологических потоков составляет 849 кВт при $\Delta t_{\min }=5^{\circ} \mathrm{C}$, при этом мощность горячих и холодных энергоносителей составляет 530 и 570 кВТ соответственно. Видно, что используется теплота перегрева аммиака и частично теплота конденсации. Всю теплоту конденсации невозможно использовать из-за структуры составных кривых и локализации точки пинча. Для достижения целевых значений мощности горячих и холодных энергоносителей, а также наилучшей рекуперации тепла необходимо использовать систему теплообменных аппаратов. Построенная сеточная диаграмма расположения теплообменных аппаратов для исследуемой системы потоков показана на рис. 4.

Сеточная диаграмма показывает, что для рекуперации 849 кВт тепловой энергии необходимо 4 теплообменника, один - в подсистеме выше 


\begin{tabular}{|l|r|c|}
\hline \multicolumn{3}{|c|}{ Компрессор } \\
\hline Мощность & 0.3210 & кВт \\
\hline Давление питания & 195.9 & кПа \\
\hline Давление продукта & 1200 & кПа \\
\hline Температура продукта & 155.2 & ${ }^{\circ} \mathrm{C}$ \\
\hline Нагрузка & 1156 & кДж/ч \\
\hline
\end{tabular}



\begin{tabular}{|l|r|c|}
\hline \multicolumn{3}{|c|}{ Испаритель } \\
\hline Нагрузка & -3733 & кДж/ч \\
\hline Температура питания & 5.318 & ${ }^{\circ} \mathrm{C}$ \\
\hline Температура продукта & -19.00 & ${ }^{\circ} \mathrm{C}$ \\
\hline
\end{tabular}

\begin{tabular}{|l|r|c|}
\hline \multicolumn{3}{|c|}{ Конденсатор } \\
\hline Нагрузка & 3956 & кДж/ч \\
\hline Температура питания & 31.00 & ${ }^{\circ} \mathrm{C}$ \\
\hline Температура продукта & 20.00 & ${ }^{\circ} \mathrm{C}$ \\
\hline
\end{tabular}

Рис. 1. Модель UniSim аммиачного холодильного цикла.

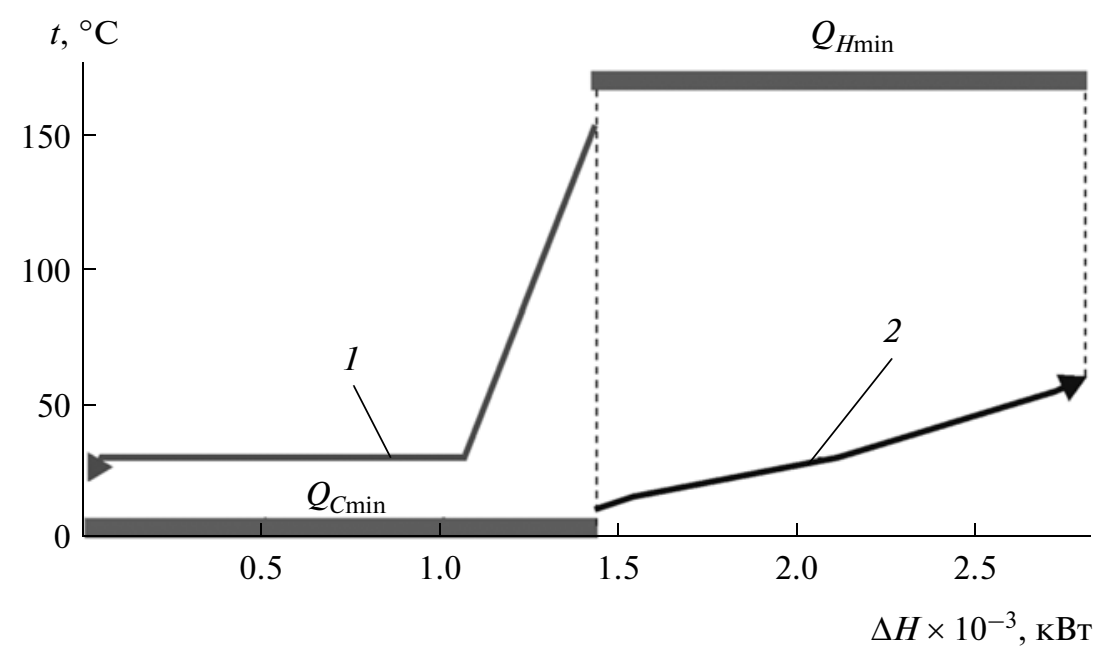

Рис. 2. Составные кривые существующей системы тепловых потоков: 1 - горячая составная кривая; 2 - холодная составная кривая.

пинча и три - в подсистеме ниже пинча. При этом мощность горячих и холодных энергоносителей составит 530 и 570 кВт, что полностью соответствует составным кривым. Поскольку $\Delta t_{\min }=$ $=5^{\circ} \mathrm{C}$ в системе теплообменников, то рекомендуется применять теплообменные аппараты пластинчатого типа. Они позволяют достичь столь малого температурного перепада на концах тепло- обменника. При этом аппараты должны быть сварные по стороне аммиака из-за высокой токсичности последнего. Ориентировочная общая площадь дополнительной теплообменной поверхности составит $225 \mathrm{~m}^{2}$. Стоимость установки 1 теплообменника принимается для расчетов в данной работе 5000 дол. США, стоимость $1 \mathrm{~m}^{2}$ теплообменной поверхности 500 дол. США [19]. На Укра- 


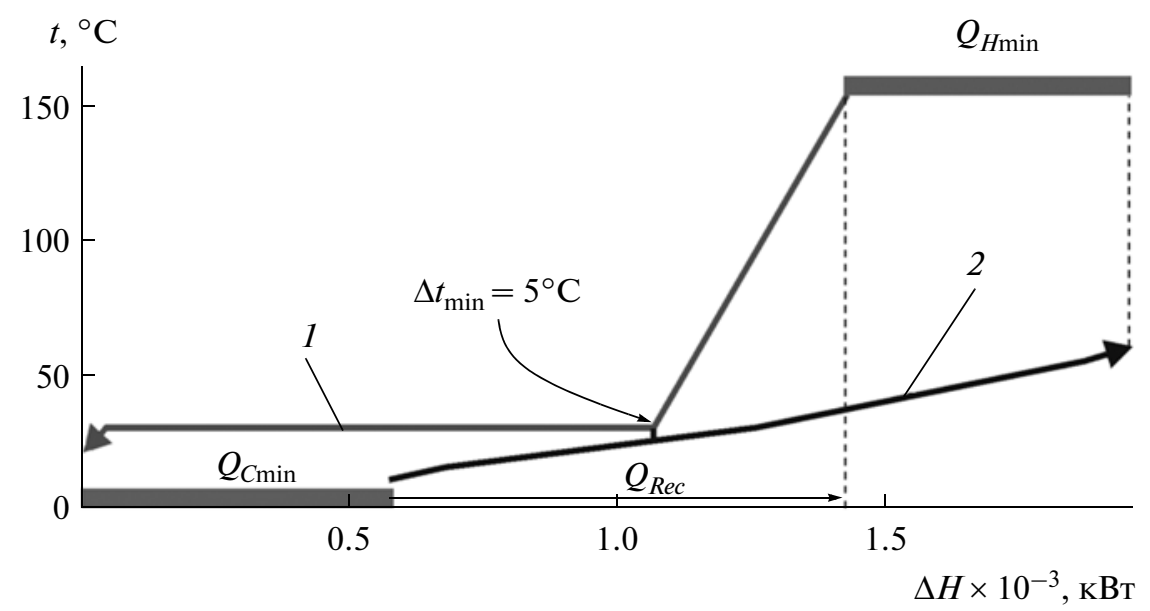

Рис. 3. Составные кривые исходного процесса для $\Delta t_{\min }=5^{\circ} \mathrm{C}: 1-$ горячая составная кривая; 2 - холодная составная кривая.

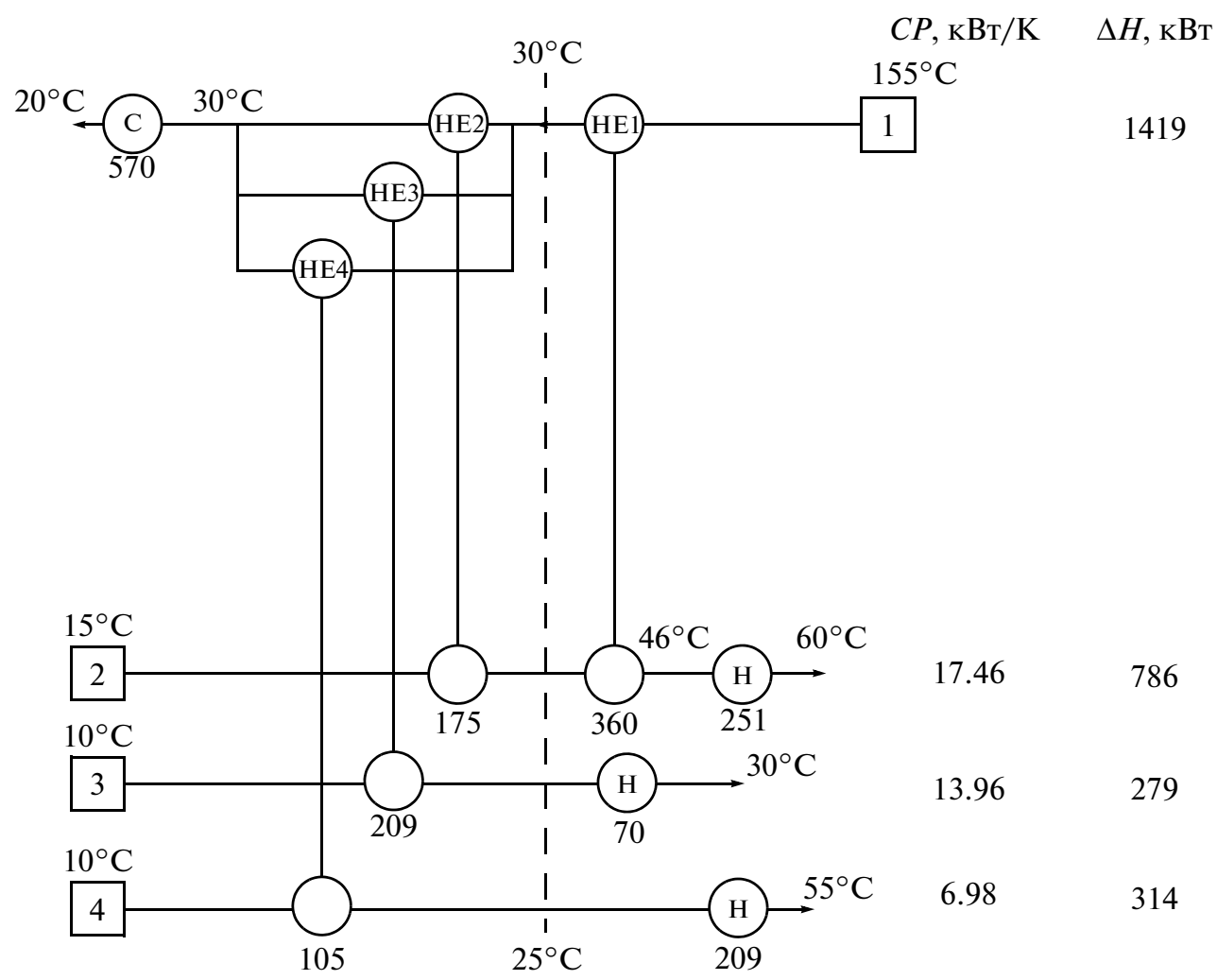

Рис. 4. Сеточная диаграмма исследуемой системы потоков для $\Delta t_{\min }=5^{\circ} \mathrm{C}$ : $\mathrm{HE} 1-4-$ рекуперативные теплообменные аппараты; C - холодильник; Н - нагреватели; пунктир показывает точку пинча.

ине стоимость горячих энергоносителей составляет ориентировочно 350 дол. США за 1 кВт год, а холодных - 35 дол. США за 1 кВт год, при этом ориентировочный срок окупаемости составляет 5 месяцев.

Дополнительное сжатие аммиака. Дополнительный анализ системы потоков показывает, что увеличив температуру конденсации можно изме- нить положение точки пинча и конфигурацию составных кривых (рис. 3) и тем самым увеличить потенциал рекуперации тепла [14]. С использованием программы UniSim Design была построена модель холодильной машины с дополнительным сжатием аммиака (рис. 5). В данной схеме аммиак охлаждается после первой ступени сжатия со 125 до $30^{\circ} \mathrm{C}$. Далее поток попадает на вторую ступень 


\begin{tabular}{|l|r|c|}
\hline \multicolumn{3}{|c|}{ Компрессор-1 } \\
\hline Мощность & 0.3210 & кВт \\
\hline Давление питания & 195.9 & кПа \\
\hline Давление продукта & 1200 & кПа \\
\hline Температура продукта & 155.2 & ${ }^{\circ} \mathrm{C}$ \\
\hline Нагрузка & 1156 & кДж/ч \\
\hline
\end{tabular}

\begin{tabular}{|l|r|c|}
\hline \multicolumn{3}{|c|}{ Компрессор-2 } \\
\hline Мощность & 0.1347 & кВт \\
\hline Давление питания & 1190 & кПа \\
\hline Давление продукта & 2604 & кПа \\
\hline Температура продукта & 111.4 & ${ }^{\circ} \mathrm{C}$ \\
\hline Нагрузка & 485.0 & кДж/ч \\
\hline
\end{tabular}

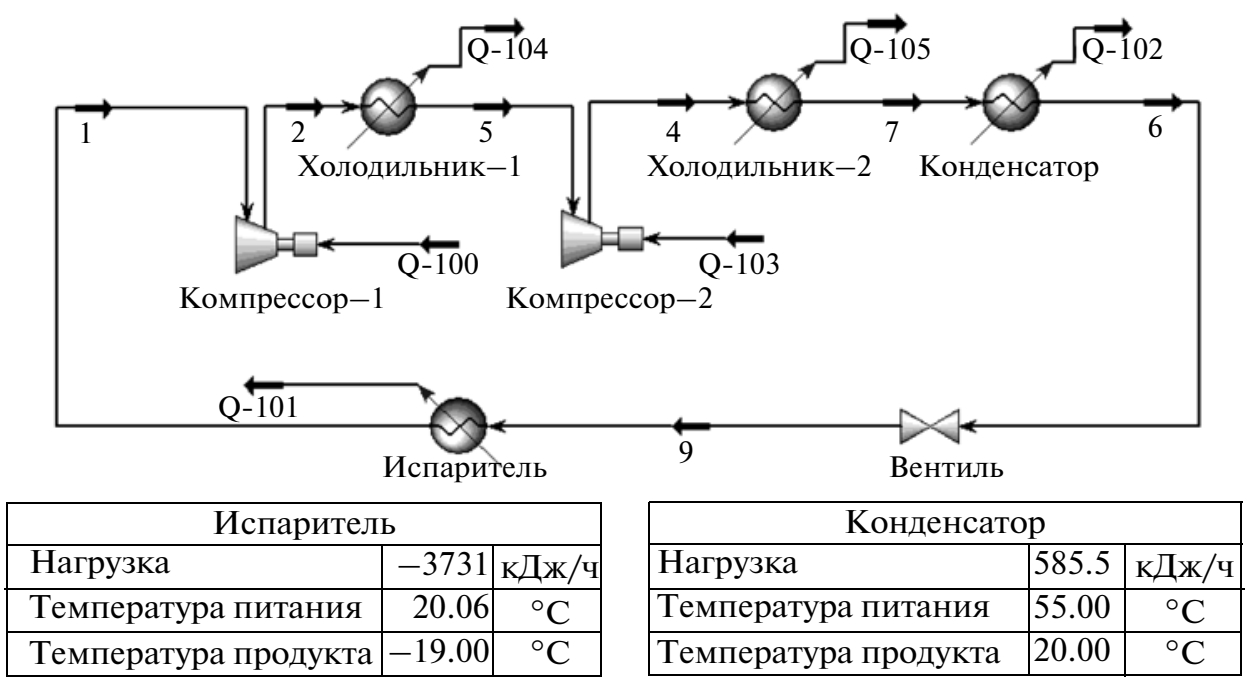

Рис. 5. Модель UniSim аммиачной холодильной машины с дополнительным компримированием.

сжатия и покидает ее с давлением 2604 кПа и температурой $111^{\circ} \mathrm{C}$. Из компрессора аммиак поступает на охлаждение и конденсацию, после чего, как и в первом случае, на дросселирование и испарение.

Компьютерная модель позволила определить все характеристики аммиачного потока в холодильном цикле с дополнительной компрессией. Это позволило сформировать таблицу параметров технологических потоков для анализа системы потоков. Параметры технологических потоков, которые могут быть включены в тепловую интеграцию, представлены в табл. 2.
Составные кривые неинтегрированного процесса с дополнительным компримированием показаны на рис. 6. Тепловая мощность, необходимая для охлаждения, составит 1517 кВт, а для нагрева всех холодных потоков - 1378 кВт.

Выбор оптимального $\Delta \boldsymbol{t}_{\min }$. Если в первом случае $\Delta t_{\min }$ выбиралась из минимально допустимой разницы, то во втором случае был проведен оптимизационный расчет. Для выбора минимальной разности температур в системе теплообменников были построены зависимости стоимости теплообменной поверхности, стоимости энергоносителей и общей приведенной стоимости от $\Delta t_{\min }$ (рис. 7).

Таблица 2. Параметры технологических потоков для системы с дополнительным компримированием

\begin{tabular}{|c|c|c|c|c|c|c|c|c|c|}
\hline № & Название потока & Тип & $t_{S},{ }^{\circ} \mathrm{C}$ & $t_{T},{ }^{\circ} \mathrm{C}$ & $G, \mathrm{~T} / \mathrm{\Psi}$ & $\begin{array}{c}C, \\
\text { кДж/(кг К) }\end{array}$ & $\begin{array}{c}r, \\
\text { кДж/кГ }\end{array}$ & $\begin{array}{c}C P \\
\mathrm{KBT} / \mathrm{K}\end{array}$ & $\Delta H, \mathrm{kB \textrm {T }}$ \\
\hline 1 & $\begin{array}{l}\text { Охлаждение аммиака } \\
\text { (первая ступень) }\end{array}$ & Горячий & 125 & 30 & 3.194 & 3.250 & - & 2.883 & 273.93 \\
\hline \multirow[t]{3}{*}{2} & $\begin{array}{l}\text { Охлаждение аммиака } \\
\text { (вторая ступень) }\end{array}$ & Горячий & 111 & 60 & 3.194 & 4.275 & - & 3.793 & 193.44 \\
\hline & Конденсация аммиака & Горячий & 60 & 60 & 3.194 & - & 986.2 & - & 874.98 \\
\hline & $\begin{array}{l}\text { Охлаждение жидкого ам- } \\
\text { миака }\end{array}$ & Горячий & 60 & 20 & 3.194 & 4.935 & - & 4.378 & 175.14 \\
\hline 3 & Подогрев воды & Холодный & 15 & 60 & 15.000 & 4.190 & - & 17.458 & 785.63 \\
\hline 4 & Подогрев воздуха & Холодный & 10 & 30 & 50.000 & 1.005 & - & 13.958 & 279.17 \\
\hline 5 & Воздух для тепловых завес & Холодный & 10 & 55 & 25.000 & 1.005 & - & 6.979 & 314.06 \\
\hline
\end{tabular}




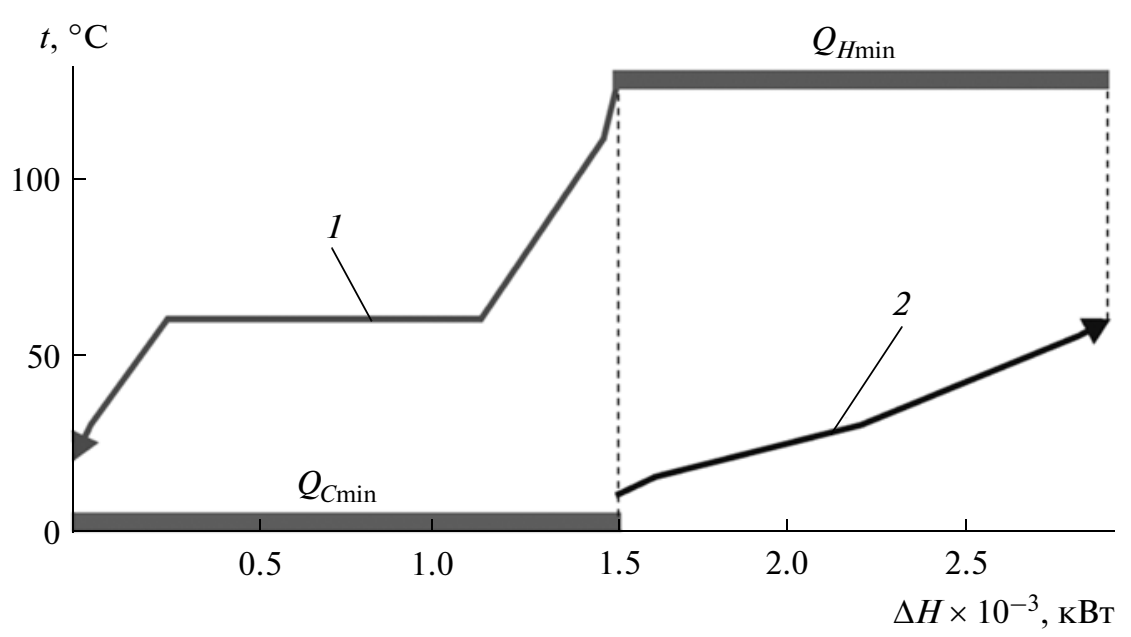

Рис. 6. Составные кривые существующей системы тепловых потоков: 1 - горячая составная кривая; 2 - холодная составная кривая.

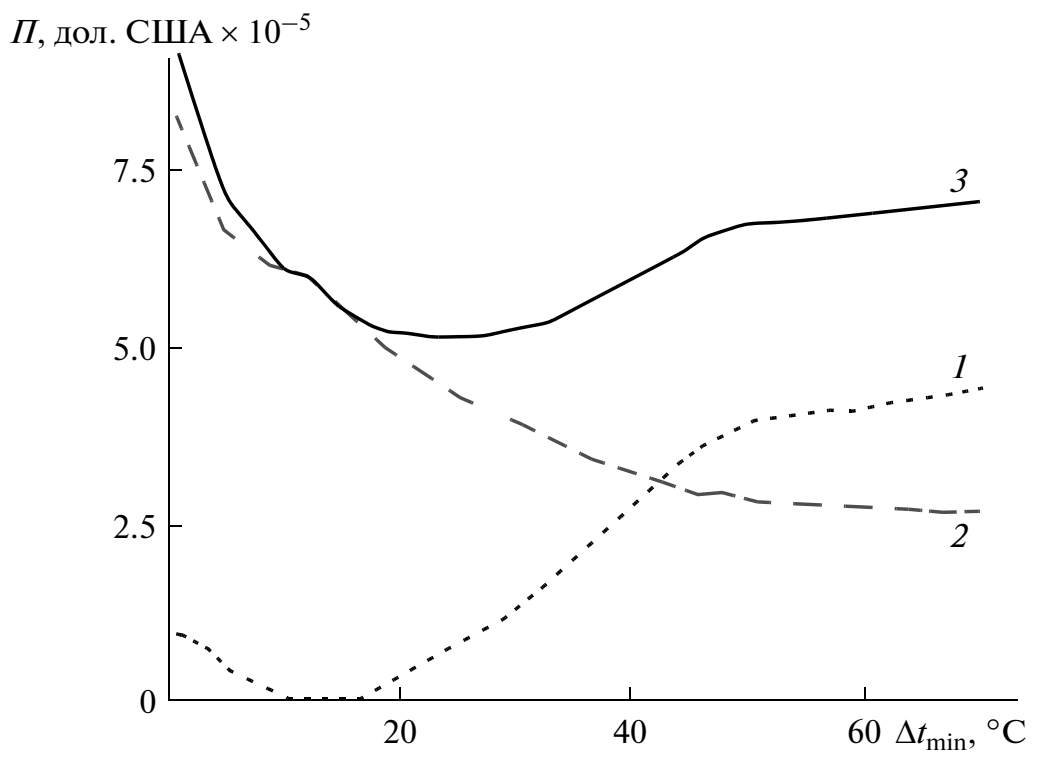

Рис. 7. Стоимостные зависимости: 1 - приведенная стоимость энергоносителей; 2 - приведенные капитальные затраты; 3 - общая приведенная стоимость.

Кривая общей приведенной стоимости имеет минимум при $\Delta t_{\min }=23^{\circ} \mathrm{C}$. Но на участке кривой от $\Delta t_{\min }=17^{\circ} \mathrm{C}$ до $\Delta t_{\min }=27^{\circ} \mathrm{C}$ общая приведенная стоимость изменяется незначительно. При этом затраты на энергоносители будут ниже при $\Delta t_{\min }=$ $=17^{\circ} \mathrm{C}$. Наличие минимума на кривой приведенной стоимости энергии (кривая 1, рис. 7) объясняется пороговым характером составных кривых [11]. Для пороговых задач, как правило, $\Delta t_{\min }$ выбирается равным $\Delta t$ порога. В нашем случае это значение равно $17^{\circ} \mathrm{C}$. Соответственно, при выбоpe $\Delta t_{\min }=17^{\circ} \mathrm{C}$ для проектирования теплообменной сети, удовлетворяются два требования, а именно: общая приведенная стоимость проекта будет близка к минимально возможной, а также $\Delta t_{\min }$ будет соответствовать пороговому значению. К тому же цены на энергоносители постоянно растут [20], и выбор меньшей разницы температур приведет к меньшим затратам в будущем.

Составные кривые технологических потоков с дополнительным компримированием, построенные для $\Delta t_{\min }=17^{\circ} \mathrm{C}$, показаны на рис. 8. Рекуперация тепла составит 1379 кВт, мощность холодных энергоносителей снижается до 139 кВт, а необходимость в горячих энергоносителях отпадает, но при этом необходимы затраты на дополнительное сжатие потока аммиака. 


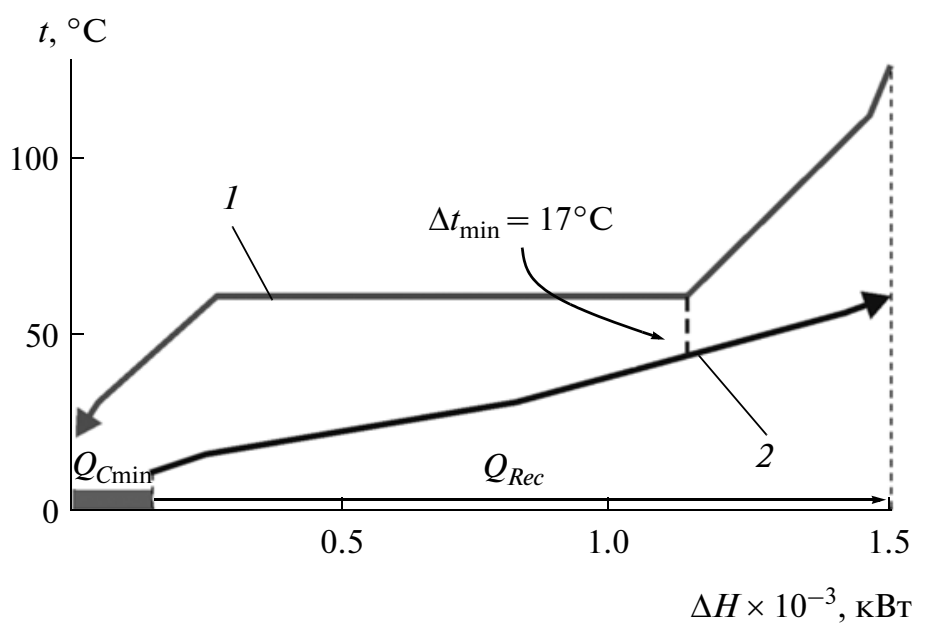

Рис. 8. Составные кривые процесса с дополнительным компримированием потока аммиака $\left(\Delta t_{\min }=17^{\circ} \mathrm{C}, Q_{\operatorname{Rec}}=\right.$ $=1379 \mathrm{\kappa B}$ ): 1 - горячая составная кривая; 2 - холодная составная кривая.

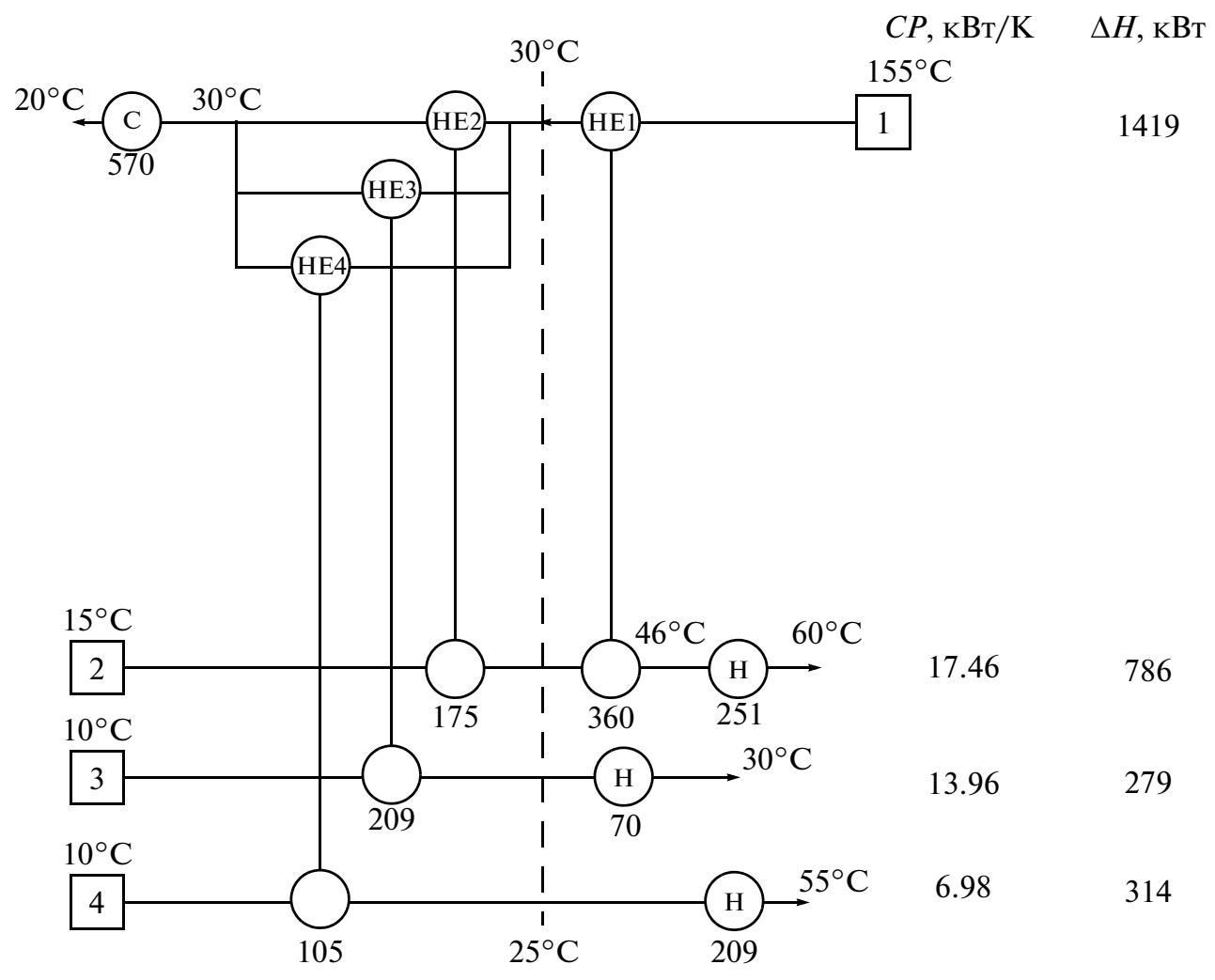

Рис. 9. Сеточная диаграмма системы потоков с дополнительным компримированием аммиака $\left(\Delta t_{\min }=17^{\circ} \mathrm{C}\right)$ : HE1-6 - рекуперативные теплообменные аппараты; С - холодильник; Н - нагреватели; пунктир показывает точку пинча.

Таким образом, применение дополнительного компримирования аммиака позволит удовлетворить потребности в нагреве всех холодных потоков системы горячими потоками, не используя энергоносители, но используя дополнительную мощность компрессора. Составные кривые также показывают локализацию точки пинча и его тем- пературы, что необходимо для построения системы теплообменников с помощью сеточной диаграммы.

Система теплообменных аппаратов. Разработанная сеточная диаграмма теплообменной сети интегрированного процесса с дополнительным компримированием показана на рис. 9. Сеточная 
диаграмма состоит из 6 рекуперативных теплообменных аппаратов с общей тепловой нагрузкой 1379 кВт и двух холодильников, для охлаждения и конденсации аммиака. Общая площадь поверхности теплообмена дополнительного оборудования ориентировочно составит 377 м², при этом нужно отметить, что в системе с дополнительным компримированием возможно использовать теплообменные аппараты любой контрукции благодаря достаточно большой минимально допустимой разности температур $17^{\circ} \mathrm{C}$. Для работы схемы с дополнительным сжатием также необходима установка компрессора, который будет потреблять 135 кВт электрической энергии. Стоимость компрессора составит ориентировочно 50000 дол. США [6]. Стоимость установки теплообменного оборудования, удельная стоимость теплообменной поверхности и стоимость энергоносителей принимается аналогичной расчетам схемы без дополнительного сжатия аммиака. При этом ориентировочный срок окупаемости проекта реконструкции схемы с использованием дополнительного компримирования потока аммиака составит 7 месяцев.

\section{ЗАКЛЮЧЕНИЕ}

Анализ работы аммиачного холодильного цикла супермаркета показал наличие возможности использования теплоты перегрева и конденсации потока аммиака. Это тепло может использоваться для подогрева воды и воздуха, что значительно сократит затраты на энергоносители. Применение дополнительного компримирования потока аммиака улучшает тепловую интеграцию, но для реализации такого проекта необходимы большие капитальные затраты. Однако экономическая оценка такого проекта реконструкции показывает его целесообразность. Эта методология может быть использована для определения капитальных затрат теплообменных сетей в пределах больших производственных комплексов, которые используют промежуточные теплоносители [21].

Также результаты данной работы могут быть использованы при реконструкции существующих и проектировании новых аммиачных холодильных циклов супермаркетов. При реализации таких проектов необходимо проводить дополнительный анализ систем энергопотребления, поскольку каждая из них обладает своим набором потоков и особенностями оборудования, а также технологическими ограничениями.

Работа выполнена при поддержке Европейской комиссии: проект INTHEAT (контракт № FP7-SME-2010-1-262205) и проект DISKNET (соглашение № PIRSES-GA-2011-294933).

\section{ОБОЗНАЧЕНИЯ}

$C P$ - теплоемкость потока, кВт/K;
$C_{p}$ - теплоемкость при постоянном давлении, кДж/(кг К);

$G-$ массовый расход, т/ч;

$\Delta H$ - энтальпия потока, кВт;

$Q_{C \min }-$ минимальная мощность холодных энергоносителей, кВт;

$Q_{H \min }-$ минимальная мощность горячих энергоносителей, кВт;

$Q_{\mathrm{Rec}}-$ мощность рекуперации, кВт;

$r$ - скрытая теплота фазового перехода, кДж/кг;

$t$ - температура, ${ }^{\circ} \mathrm{C}$;

$t_{S}-$ начальная температура, ${ }^{\circ} \mathrm{C}$;

$t_{T}-$ конечная температура, ${ }^{\circ} \mathrm{C}$;

$\Delta t$ - разность температур, ${ }^{\circ} \mathrm{C}$;

$\Delta t_{\min }-$ минимальная температурная разность, ${ }^{\circ} \mathrm{C}$; П - приведенная стоимость, дол. США.

\section{ИНДЕКСЫ}

Cmin - минимальная мощность холодных энергоносителей;

Hmin - минимальная мощность горячих энергоносителей;

$\min$ - минимальное значение;

$\operatorname{Rec}$ - рекуперация;

$S$ - начальная температура;

$T$ - конечная температура.

\section{СПИСОК ЛИТЕРАТУРЫ}

1. Klemě̌ J., Perry S.J. Process optimisation to minimise energy use in food processing // Handbook of waste management and co-product recovery in food processing. V. 1. Cambridge: Woodhead Publishing Limited, 2007. P. 59.

2. Klemě̌ J.J., Varbanov P.S., Pierucci S. Process sustainability and operability via integration, energy saving and pollution reduction // Theor. Found. Chem. Eng. 2012. V. 46. № 6. P. 1.

3. Klemě̌ J., Friedler F., Bulatov I., Varbanov P. Sustainability in the Process industry - Integration and Optimization. New York: McGraw-Hill, 2010.

4. Товажнянский Л.Л., Капустенко П.А., Ульев Л.М., Болдырев С.А., Арсеньева О.П., Тарновский М.В. Интеграция тепловых процессов на установке первичной переработки нефти АВТ А12/2 при работе в зимнее время // Теорет. основы хим. технологии. 2009. T. 43. № 6. С. 665.

5. Мешалкин В.П., Бояринов Ю.Г. Полумарковские модели функционирования сложных химико-технологических систем // Теорет. основы хим. технологии. 2010. Т. 44. № 2. С. 198.

6. Nemet A., Varbanov P., Klemeš J.J. Waste-to-Energy Technologies Performance Evaluation Techniques // Chemical Engineering Transactions. 2011. V. 25. P. 513.

7. Reay D.A., Macmichael D.B.A. Heat pumps: design and applications. Oxford: Pergamon Press, 1988. 
8. Горшков В.Г. Тепловые насосы. Аналитический обзор // Справочник промышленного оборудования. 2004. № 2. С. 47.

9. Calm J.M. Heat pumps in the USA // Int. J. Refrig. 1987. V. 10. № 4. P. 190.

10. Korfitsen E., Kristensen A.P.R. Ammonia high pressure heat pumps in food refrigeration applications // Int. J. Refrig. 1998. № 21(3). P. 212.

11. Kemp I.C. Pinch Analysis and Process Integration: A User Guide on Process Integration for the Efficient Use of Energy. 2nd ed. Oxford: Butterworth-Heinemann, 2007.

12. Smith $R$. Chemical process design and integration. Chichester: John Wiley \& Sons Ltd, 2005.

13. Смит Р., Клемеш Й., Товажнянский Л.Л., Капустенко П.А., Ульев Л.М. Основы интеграции тепловых процессов. Харьков: НТУ «ХПИ», 2000.

14. Becker H., Maréchal F. Targeting industrial heat pump integration in multi-period problems // Comput. Aided Chem. Eng. 2012. V. 31. P. 415.

15. Klemě̌ J.J., Varbanov P.S. Heat integration including heat exchangers, combined heat and power, heat pumps, separation processes and process control // Appl. Therm. Eng. 2012. V. 43. P. 1.

16. Kapustenko P.O., Ulyev L.M., Boldyryev S.A., Garev A.O. Integration of heat pump into the heat supply system of cheese production plant // Energy. 2008. V. 33. № 6. P. 882.

17. Щербин B.A. Холодильные станции и установки. М.: Химия, 1976.

18. UniSim Design Software [Электронный ресурс]. Режим доступа: Ahpsweb.honeywell.com/Cultures/ en-US/Products/ControlApplications/simulation/ UniSimDesign/default.htm (дата обращения: 10.09.2012).

19. ALFA LAVAL [Электронный ресурс]. Режим доступа: www.alfalaval.com/Pages/default.aspx (дата обращения: 22.08.2012).

20. Nemet A., Klemeš J.J., Kravanja Z. Minimisation of a heat exchanger networks' cost over its entire lifetime // Energy. 2012. V. 33. № 6. P. 882.

21. Nemet A., Varbanov P.S., Kapustenko P., Boldyryev S., Klemeš J.J. Capital Cost Targeting of Total Site Heat Recovery // Chemical Engineering Transaction. 2012. V. 29. P. 1447. 